\title{
Epidemiology of pediatric acute respiratory distress syndrome in Singapore: risk factors and predictive respiratory indices for mortality
}

\section{Judith Ju-Ming Wong ${ }^{1}$, Tsee Foong Loh ${ }^{2,3}$, Daniela Testoni ${ }^{4}$, Joo Guan Yeo ${ }^{2}$, Yee Hui Mok ${ }^{2}$ and Jan Hau Lee ${ }^{2,3 *}$}

' Department of Pediatric Medicine, KK Women's and Children's Hospital, Singapore, Singapore

${ }^{2}$ Children's Intensive Care Unit, Department of Pediatric Subspecialties, KK Women's and Children's Hospital, Singapore, Singapore

${ }^{3}$ Duke-NUS Graduate School of Medicine, Singapore, Singapore

${ }^{4}$ Division of Neonatal Medicine, Escola Paulista de Medicina, Universidade Federal de São Paulo, São Paulo, Brazil

\section{Edited by:}

James Donald Fortenberry, Emory

University School of Medicine, USA

\section{Reviewed by:}

Christine Uta Vohwinkel, University of Colorado Denver Medical School, USA Atul Vats, Emory University, USA

\section{*Correspondence:}

Jan Hau Lee, Children's Intensive Care Unit, KK Women's and Children's Hospital, 100 Bukit Timah Road, 229899 Singapore e-mail: leejanhau@hotmail.com
Aim: Acute respiratory distress syndrome (ARDS) represents the most severe form of acute lung injury. The aim of our study is to describe the epidemiology of pediatric ARDS in Singapore and compare the outcomes of ARDS using the following respiratory indices: $\mathrm{P}_{\mathrm{a}} \mathrm{O}_{2} / \mathrm{F}_{\mathrm{i}} \mathrm{O}_{2}$ ratio (P/F ratio), $\mathrm{S}_{\mathrm{p}} \mathrm{O}_{2} / \mathrm{F}_{\mathrm{i}} \mathrm{O}_{2}$ ratio ( $\mathrm{S} / \mathrm{F}$ ratio), oxygenation index (OI), and oxygen saturation index (OSI).

Methods: We examined medical records of patients admitted to the Children's Intensive Care Unit in KK Women's and Children's Hospital from 2009 to 2012. Those who fulfilled criteria for the American-European Consensus Conference definition for ARDS were identified. Demographic, clinical, and radiographic information were extracted and analyzed.

Results: We identified 70 patients with ARDS. Median age (interquartile range) was 6.2 $(1.4,10.4)$ years. The most common risk factor was pneumonia [50 (71\%)]. Overall mortality was $44(63 \%)$ patients. Thirty-two (56\%) patients had an underlying chronic comorbidity; $18(46 \%)$ were hematology-oncology conditions. Fifty-six (80\%) patients had multiorgan dysfunction. Adjunct therapies used in our patients included inhaled nitric oxide [5 (7\%)], prone position [22 (31\%)], steroids [26 (37\%)], and neuromuscular blockade [26 (37\%)]. A high $\mathrm{Ol}$ and low PF ratio after $24 \mathrm{~h}$ of diagnosis of ARDS were associated with mortality. From day 3 onward, all four respiratory indices appropriately differentiated survivors from non-survivors. Severity based on the S/F ratio and OSI demonstrated association with decreased ventilator free days and ICU free days.

Conclusion: Risk factors for mortality included having an underlying comorbidity, multiorgan dysfunction, a low PF ratio, and high Ol at $24 \mathrm{~h}$ of ARDS. Abnormal $\mathrm{S}_{\mathrm{p}} \mathrm{O}_{2}$-based measurements were reliable markers of poor outcomes in pediatric ARDS.

Keywords: acute respiratory distress syndrome, acute lung injury, critical care, children, pediatric intensive care unit, epidemiology, pulse oximetry, Asia

\section{INTRODUCTION}

Acute respiratory distress syndrome (ARDS) represents the most severe form of acute lung injury (ALI) and is characterized by alveolar leukocyte infiltration and protein-rich pulmonary edema (1). Compared with those without lung injury, children with ALI/ARDS have significant increased morbidity and mortality in the pediatric intensive care unit (PICU) $(1,2)$.

Compared to adults, the incidence of ARDS is lower in children (1-4\% of all PICU admissions) (3). Mortality from pediatric ARDS varies widely between 20 and $62 \%(1,2,4-$ 8). In contrast to data from adults where mortality from ARDS has declined from approximately $64-70 \%$ in the 1980 s to $29-42 \%$ in the twenty-first century, similar trends have not been demonstrated in the pediatric literature (9-13). The epidemiology of pediatric ARDS in Singapore has not been previously described.

The most well accepted definition for pediatric ARDS is extrapolated from the adult definition based on the American-European Consensus Conference (AECC), which utilizes the arterial partial pressure of oxygen $\left(\mathrm{P}_{\mathrm{a}} \mathrm{O}_{2}\right)$ to fraction of inspired oxygen $\left(\mathrm{F}_{\mathrm{i}} \mathrm{O}_{2}\right)$ $(\mathrm{P} / \mathrm{F})$ ratio $(14,15)$. Another $\mathrm{P}_{\mathrm{a}} \mathrm{O}_{2}$-based index, oxygenation index (OI), has the inherent advantage over $\mathrm{P} / \mathrm{F}$ ratio through the incorporation of the mean airway pressure (MAP). A higher OI in itself has been shown to independently predict mortality $(1,16-$ 19). Due to challenges in placing arterial catheters to periodically measure the $\mathrm{P}_{\mathrm{a}} \mathrm{O}_{2}$ in children, investigators have utilized and validated respiratory indices using non-invasive oxygen saturation $\left(\mathrm{S}_{\mathrm{p}} \mathrm{O}_{2}\right)$-based measurements $(14,20)$. 
The primary aim of this study is to describe the epidemiology of pediatric ALI/ARDS in Singapore. The optimal variable to quantify oxygenation impairment for risk stratification remains uncertain (20). Therefore, our study's secondary aim is to compare the outcomes of ALI/ARDS using both $\mathrm{P}_{\mathrm{a}} \mathrm{O}_{2}$-based indices $(\mathrm{P} / \mathrm{F}$ ratio and $\mathrm{OI})$ and $\mathrm{S}_{\mathrm{p}} \mathrm{O}_{2}$-based indices $\left[\mathrm{S}_{\mathrm{p}} \mathrm{O}_{2} / \mathrm{F}_{\mathrm{i}} \mathrm{O}_{2}\right.$ ratio $(\mathrm{S} / \mathrm{F}$ ratio) and oxygen saturation index (OSI)].

\section{MATERIALS AND METHODS PATIENTS}

We collected data on all patients admitted to our Children's Intensive Care Unit (CICU) over a 4-year period (January 1, 2009 to December 31, 2012). Our hospital is one of two tertiary pediatric centers in Singapore that receives national and regional pediatric referrals. Our CICU is a 16-bedded multidisciplinary facility that admits medical, surgical, and cardio-thoracic patients. This study has been approved by our hospital's institutional review board and a waiver of consent was granted.

In our institution, all hospitalized patients are coded using either the International Classification of Diseases [ICD9CM or ICD10AM (from 2012 onward)] or the SCT (SNOMED CLINICAL TERMINOLOGY) code. We generated a patient list with ALI/ARDS using these codes. We then examined patients' charts to confirm that these patients fulfilled criteria for the AECC's definition for ALI/ARDS. In addition, an independent search of the CICU's admission log was also performed, identifying all patients that fulfilled the AECC definition of ALI/ARDS, regardless whether they had been coded as such, to ensure a complete pick up rate.

We included all patients aged 1 day to 16 years of age that had either a primary or secondary diagnosis of ALI/ARDS in their discharge or death summaries. Premature neonates (gestational age $<35$ weeks), inborn neonates, and patients being cared for in the neonatal intensive care unit (NICU) were excluded.

\section{DATA COLLECTION}

Demographic, clinical, and radiographic data were extracted through chart review using a standardized data collection form. Severity of illness scores including the PRISM 2 and PELOD score were taken on PICU admission. We recorded arterial blood gas measurements and ventilator modes on day of diagnosis, $24 \mathrm{~h}$, day 3 , and day 7 of ALI/ARDS. We also collected data on adjunct therapies used for ARDS including inhaled nitric oxide, prone position, steroids and neuromuscular blockade, as well as, the use of other support modalities [e.g., inotropes, continuous renal replacement therapy, and extracorporeal membrane oxygenation (ECMO)]. Positive blood cultures were also recorded.

\section{DEFINITIONS}

We defined mortality as all deaths occurring during the CICU stay. To account for death as a competing outcome, we summarized the requirement for mechanical ventilation as being free and alive from mechanical ventilation with a maximum of 28 days from the diagnosis of ALI/ARDS [28-ventilator free days (VFD)]. Similarly, in addition to length of CICU stay, we also calculated CICUfree days with a maximum of 28 days [28-ICU free days (IFD)]. Steroid exposure was defined as any use of systemic corticosteroids. We assessed for organ dysfunction on day 7 of ARDS or death,
Table 1 | Respiratory indices used to define ALI/ARDS

\begin{tabular}{llll}
\hline Index & ALI criteria & ARDS criteria & \\
\hline P/F ratio & $200-300$ (mild) $^{\mathrm{a}}$ & $<200$ (moderate) $^{\mathrm{a}}$ & $<100$ (severe) $^{\mathrm{a}}$ \\
S/F ratio & $212-253$ & $<212$ & \\
$\mathrm{OI}^{\mathrm{b}}$ & $5.3-8.1$ & $>8.1$ & \\
$\mathrm{OSI}^{\mathrm{C}}$ & $6.5-7.8$ & $>7.8$ & \\
\hline
\end{tabular}

$A L I$ - acute lung injury.

ARDS - acute respiratory distress syndrome.

$P / F$ ratio - partial pressure of arterial oxygen $\left(\mathrm{P}_{a} \mathrm{O}_{2}\right)$ : fraction of inspired oxygen ratio $\left(\mathrm{F}_{i} \mathrm{O}_{2}\right)$.

$S / F$ ratio - oxygen saturation $\left(\mathrm{S}_{p} \mathrm{O}_{2}\right)$ : fraction of inspired oxygen ratio.

${ }^{a}$ Berlin definition sub-classifies ARDS to mild, moderate, and severe based on the $P / F$ ratio.

${ }^{b} \mathrm{OI}$ - oxygenation index $=$ mean airway pressure $\times \mathrm{F}_{i} \mathrm{O}_{2} / \mathrm{P}_{a} \mathrm{O}_{2}$.

${ }^{c} \mathrm{OSI}$ - oxygen saturation index $=$ mean airway pressure $\times \mathrm{F}_{i} \mathrm{O}_{2} / \mathrm{S}_{p} \mathrm{O}_{2}$.

whichever was earlier. We utilized the International Pediatric Sepsis Consensus Conference 2005 criteria for organ dysfunction (21). We defined multiorgan dysfunction when two or more extra-pulmonary organ systems were involved. We considered any pneumothorax, pneumomediastinum, or pneumopericardium as respiratory complications from mechanical ventilation. Cut offs for ALI and ARDS for the four respiratory indices are summarized in Table 1.

\section{STATISTICAL ANALYSIS}

Categorical data were presented as counts and percentages and continuous data were presented as medians and interquartile ranges (IQR). Differences between categorical variables were analyzed using the chi-square test or Fisher's exact test, whichever was appropriate. Differences between continuous variables were analyzed using the Wilcoxon's signed rank test. Statistical analysis was performed using Stata 13.1 (College Station, TX, USA). All statistical tests were two-tailed and the significance level was taken as $p<0.05$. Risk factors for mortality were corrected for PRISM 2 scores using bivariate analysis. We did not perform the bivariate analysis for $\mathrm{P} / \mathrm{F}$ ratio and $\mathrm{OI}$ because the components of these indices are also part of the PRISM 2 score.

\section{RESULTS}

We had a total 4079 CICU admissions between years 2009 and 2012. Of these, 70 patients (17.2 per $1000 \mathrm{CICU}$ admissions or $1.7 \%$ ) fulfilled the AECC's criteria for ALI/ARDS (Table 2). The median age of our cohort was $6.0(1.4,10.4)$ years. The overall median of PRISM 2 and PELOD score was $12(7,17)$ and $12(1$, $22)$, respectively. The common risk factors included pneumonia, which was present in 50 (71\%) of patients and sepsis, which was present in 38 (54\%) of patients. Overall, at diagnosis of ALI/ARDS, our cohort had a median $\mathrm{P} / \mathrm{F}$ ratio of $112.6(71.6,147.8), \mathrm{S} / \mathrm{F}$ ratio of $130.5(100.0,163.3)$, OI of $17.3(11.3,33.3)$, and OSI of 21.1 $(12.9,29.0)$.

The overall median length of ICU and hospital stay was 10 $(4,19)$ and $19(7,57)$ days, respectively. The median IFD was 0 $(0,10)$ days. Forty-four $(63 \%)$ patients in our cohort died and 4 (5.7\%) required ECMO support. The overall median duration of 
Table 2 | Characteristics of pediatric patients with ALI/ARDS

\begin{tabular}{lccc}
\hline Characteristic & $\begin{array}{c}\text { Survivors } \\
(\boldsymbol{n = 2 6 )}\end{array}$ & $\begin{array}{l}\text { Non-survivors } \\
(\boldsymbol{n}=\mathbf{4 4})\end{array}$ & $\boldsymbol{P}$-value \\
\hline Age (years) & $4.4(1.0,8.8)$ & $7.7(1.4,11.1)$ & 0.331 \\
Age category & $7(35 \%)$ & $13(65 \%)$ & 0.670 \\
$<2$ years & $15(44 \%)$ & $21(56 \%)$ & \\
2-12 years & $4(29 \%)$ & $10(71 \%)$ & \\
$>12$ years & $15.8(10.0,25.0)$ & $18.0(8.7,35.5)$ & 0.589 \\
Weight (kg) & $8.5(4.5,14.8)$ & $12.5(7,20.0)$ & 0.121 \\
PRISM 2 score & $11.5(1,12.0)$ & $12(1,24.8)$ & 0.156 \\
PELOD score & $16(62 \%)$ & $40(91 \%)$ & $0.008^{*}$ \\
Multiorgan dysfunction ${ }^{a}$ & $8(31 \%)$ & $31(70 \%)$ & $0.001^{*}$ \\
Presence of comorbidities & 1 & 6 & \\
Neuromuscular & 0 & 4 & \\
Cardiovascular & 1 & 6 & \\
Respiratory & 0 & 0 & \\
Renal & 0 & 2 & \\
Gastrointestinal & 2 & 16 & \\
Hematology-oncology & 1 & 0 & \\
Metabolic & 3 & 2 & \\
Genetic/congenital & & & \\
& & &
\end{tabular}

Values are in median (interquartile range) and counts (percentages).

PRISM 2 - Pediatric risk of mortality.

PELOD - Pediatric logistic organ dysfunction.

${ }^{a}$ Defined as two or more extra-pulmonary organ dysfunction

${ }^{*}$ Statistically significant $(p<0.05)$.

ventilation was $10(4,21)$ days and overall median VFD was $0(0$, 13) days. Thirty-nine (56\%) patients had a chronic comorbidity and $56(80 \%)$ had multiorgan dysfunction. Presence of comorbidities and multiorgan dysfunction were associated with mortality even after adjusting for severity of illness (Table 2).

A total of $7(10 \%)$ patients did not require invasive mechanical ventilation at the onset of ALI/ARDS. Among those that required invasive mechanical ventilation, the most common mode of ventilation at diagnosis was pressure-synchronized intermittent mandatory ventilation (P-SIMV) [32 (47\%)] followed by airway pressure release ventilation (APRV) [21 (30\%)]. However, the mode of ventilation changed over the course of illness with increasing usage of APRV and high-frequency oscillatory ventilator (HFOV) after $24 \mathrm{~h}$ of diagnosis of ALI/ARDS (Figure 1).

Adjunct therapies that were used included inhaled nitric oxide, prone position, steroids, and neuromuscular blockade (Table 3). In patients who required the use of neuromuscular blockade, the median duration of therapy was $4.5(3.0,9.0)$ days. Steroid exposure occurred in $26(37 \%)$ patients for various indications including refractory shock $(n=7)$, respiratory (e.g., pneumonitis, chronic lung disease, and fibrotic stage ARDS) $(n=12)$, and other (e.g., pre-medications and drug reactions) $(n=7)$.

Sixteen $(23 \%)$ patients had positive blood cultures and the commonest organism was streptococcus sp. $(n=4)$ followed by staphylococcus $\mathrm{sp}$. $(n=3)$ and pseudomonas aeruginosa $(n=3)$. A total of $15(21 \%)$ patients had complications of air leak including pneumothorax, pneumomediastinum, and pneumopericardium.

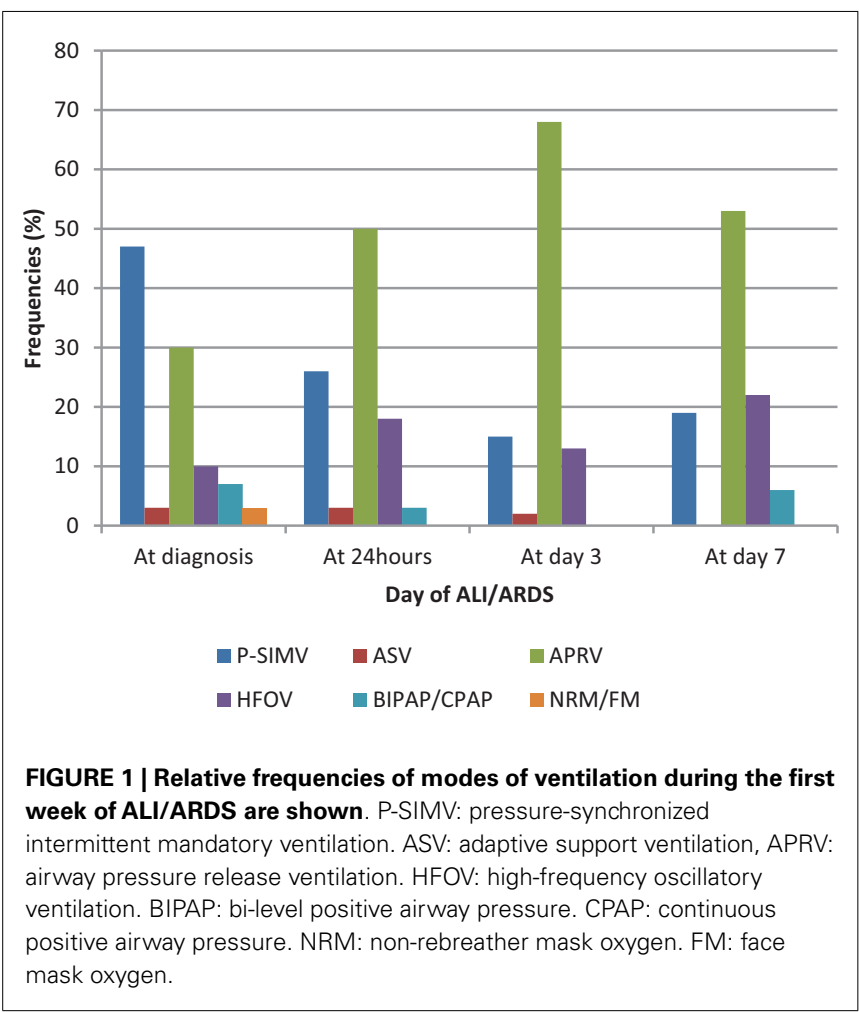

Table 3 | Use of adjunct therapies for ARDS and other supportive therapies

\begin{tabular}{lrcl}
\hline $\begin{array}{l}\text { Adjunct therapies/ } \\
\text { supportive therapies }\end{array}$ & $\begin{array}{l}\text { Survivors } \\
(\boldsymbol{n}=\mathbf{2 6})\end{array}$ & $\begin{array}{l}\text { Non-survivors } \\
(\boldsymbol{n}=\mathbf{4 4 )}\end{array}$ & $\boldsymbol{P}$-value \\
\hline iNO & 2 & 3 & 0.619 \\
Prone & 10 & 12 & 0.330 \\
Steroid exposure & 5 & 21 & $0.017^{*}$ \\
Neuromuscular blockade & 10 & 16 & 0.861 \\
Inotropes & 19 & 38 & 0.167 \\
CRRT & 3 & 7 & 0.449 \\
ECMO & 3 & 1 & 0.141 \\
\hline
\end{tabular}

ARDS - acute respiratory distress syndrome.

iNO - inhaled nitric oxide.

CRRT - continuous renal replacement therapy.

ECMO - extracorporeal membrane oxygenation.

${ }^{*}$ Statistically significant $(p<0.05)$.

There was no significant difference between all the respiratory indices at diagnosis of ALI/ARDS among survivors and non-survivors. However, both $\mathrm{P}_{\mathrm{a}} \mathrm{O}_{2}$-based indices (high $\mathrm{OI}$ and low $\mathrm{P} / \mathrm{F}$ ratio) after $24 \mathrm{~h}$ of diagnosis of ARDS onward were associated with mortality but not $\mathrm{S}_{\mathrm{p}} \mathrm{O}_{2}$-based indices. From day 3 onward, all four indices were able to differentiate patients with increased mortality (Table 4).

$\mathrm{S}_{\mathrm{p}} \mathrm{O}_{2}$-based indices were associated with VFD and IFD, a low $\mathrm{S} / \mathrm{F}$ ratio at diagnosis was associated with decreased VFD and IFD, and a high OSI at $24 \mathrm{~h}$ of ARDS was associated with decreased IFD. There was no association between $\mathrm{P}_{\mathrm{a}} \mathrm{O}_{2}$-based indices $(\mathrm{P} / \mathrm{F}$ ratio and OI) with VFD and IFD. 
Table 4 | Respiratory indices at the onset, after $24 \mathrm{~h}$, on day 3, and on day 7 of diagnosis of ALI/ARDS.

\begin{tabular}{|c|c|c|c|}
\hline $\begin{array}{l}\text { Respiratory } \\
\text { indices }\end{array}$ & $\begin{array}{l}\text { Survivors } \\
(n=26)\end{array}$ & $\begin{array}{l}\text { Non-survivors } \\
(n=44)\end{array}$ & $P$-value \\
\hline \multicolumn{4}{|c|}{ AT DIAGNOSIS } \\
\hline $\mathrm{P} / \mathrm{F}$ ratio & $123(92,148)$ & $107(65,154)$ & 0.258 \\
\hline S/F ratio & $138(116,180)$ & $121(92,162)$ & 0.175 \\
\hline Ol & $16(14,27)$ & $19(11,34)$ & 0.375 \\
\hline OSI & $19(13,30)$ & $22(13,28)$ & 0.764 \\
\hline \multicolumn{4}{|l|}{ AT $24 \mathrm{~h}$} \\
\hline $\mathrm{P} / \mathrm{F}$ ratio & $160(124,255)$ & $103(63,188)$ & $0.011^{*}$ \\
\hline S/F ratio & $192(140,222)$ & $137(99,218)$ & 0.071 \\
\hline Ol & $12(7,23)$ & $23(10,41)$ & $0.038^{*}$ \\
\hline OSI & $12(8,18)$ & $18(9,29)$ & 0.145 \\
\hline \multicolumn{4}{|l|}{ AT DAY 3} \\
\hline $\mathrm{P} / \mathrm{F}$ ratio & $180(123,276)$ & $106(60,212)$ & $0.006^{*}$ \\
\hline S/F ratio & $221(170,303)$ & $149(91,243)$ & $0.006^{*}$ \\
\hline Ol & $12(6,17)$ & $25(7,53)$ & $0.022^{*}$ \\
\hline OSI & $10(7,13)$ & $18(8,33)$ & $0.010 *$ \\
\hline \multicolumn{4}{|l|}{ AT DAY 7} \\
\hline $\mathrm{P} / \mathrm{F}$ ratio & $219(155,293)$ & $124(66,226)$ & $0.010^{*}$ \\
\hline $\mathrm{S} / \mathrm{F}$ ratio & $277(175,330)$ & $146(102,222)$ & $0.002^{*}$ \\
\hline Ol & $8(6,13)$ & $22(8,49)$ & $0.016^{*}$ \\
\hline OSI & $7(6,12)$ & $20(9,30)$ & $0.013^{*}$ \\
\hline
\end{tabular}

Values are in median (interquartile range).

ALI - acute lung injury.

ARDS - acute respiratory distress syndrome.

P/F ratio - partial pressure of arterial oxygen: fraction of inspired oxygen ratio.

$S / F$ ratio-oxygen saturation: fraction of inspired oxygen ratio.

Ol-oxygenation index.

OSI - oxygenation saturation index.

${ }^{*}$ Statistically significant $(p<0.05)$.

\section{DISCUSSION}

Our study demonstrated that ALI/ARDS occurred in approximately $2 \%$ of all CICU admissions. Overall mortality remained very high. This study highlighted the following: (1) there was a trend toward the use of alternative modes of mechanical ventilation (e.g., APRV, HFOV); (2) a lower P/F ratio and higher OI after $24 \mathrm{~h}$ of diagnosis of ARDS were associated with increased mortality; and (3) $\mathrm{SpO}_{2}$-based measurements were as reliable as $\mathrm{P}_{\mathrm{a}} \mathrm{O}_{2}$-based indices to quantify oxygenation failure (especially after 3 days of ARDS onset).

There are several similarities between our study's findings and those reported previously. Our incidence of ALI/ARDS of 1.7\% of all CICU admissions was consistent with previous reports (0.6$7 \%)(1,2,4-6)$. The causes and risk factors of ARDS in our population were also similar to other reports and predominantly involved pneumonia and sepsis $(1,22)$. The need for ECMO support in our cohort was 5.7\% $(n=4)$, which was similar to other centers in Australia/New Zealand (3.4\%) (1). However, some centers in France reported the use of ECMO to be as high as $22 \%$ (2).

The CICU mortality rate from ALI/ARDS in our study $(63 \%)$ was higher compared with other pediatric ARDS reports (20-35\%) $(1,5,6,8,22)$. However, there are scattered reports of higher mortality numbers ranging from 60 to $63 \%(2,4,23)$. The high mortality rates in our cohort can be attributed to the fact that a large majority (91\%) of our patients satisfied the ARDS criteria $(\mathrm{P} / \mathrm{F}$ ratio $<200)$ rather than $\mathrm{ALI}(\mathrm{P} / \mathrm{F}$ ratio $200-300)$ at diagnosis. In addition, more than half of our cohort also had an underlying chronic comorbidity (56\%). Among those with comorbidities, hematology-oncology diagnoses were the most common (46\%). Pre-existing chronic organ dysfunction and immunosuppression have been associated with increased mortality in pediatric ALI/ARDS (1, 2, 23). Excluding hematology-oncology patients, mortality rate in our cohort was $53.8 \%$. Moreover, $80 \%$ of our cohort had multiorgan dysfunction.

The most common initial mode of ventilation was pressure controlled ventilation. This reflects the mode with which most pediatric intensivists are traditionally comfortable with $(22,24)$. This utility of this mode, however, steadily declined as the disease progressed and other modes of ventilation were adopted. HFOV has been used to improve oxygenation in pediatric patients with ARDS and severe hypoxemia refractory to conventional ventilatory support (25-27). The evidence for APRV specifically in improving oxygenation in pediatric ARDS is growing; however, the only ventilation strategy that has been conclusively associated with improved outcomes is the use of low tidal volumes $(23,28$ 30). Till date, there are no randomized controlled trials comparing APRV to other modes of ventilation.

The P/F ratio features prominently in multiple definitions for ARDS including the AECC definition, the Berlin definition, the Murray lung injury score (or Pediatric lung injury score), and the Delphi consensus panel definition (31-34). This index requires arterial blood gas sampling, which is difficult to obtain in some children, thus rendering the $\mathrm{P} / \mathrm{F}$ ratio problematic for early diagnosis and monitoring. Indeed, a small number of the patients in our cohort had missing data due to failure in obtaining arterial samples [10/280 (3\%) of blood gas samples were capillary samples and were excluded from the analysis]. The use of the S/F ratio in ARDS diagnosis was previously described in two pediatric trials $(14,20)$. The oxyhemoglobin dissociation curve is nearly linear when $\mathrm{S}_{\mathrm{p}} \mathrm{O}_{2}$ is between 80 and $97 \%$. Subsequently, it levels off such that a large increment in $\mathrm{P}_{\mathrm{a}} \mathrm{O}_{2}$ produces only a tiny increment in $\mathrm{S}_{\mathrm{p}} \mathrm{O}_{2}$. Therefore, it may be possible to characterize pediatric ALI/ARDS accurately by substituting $\mathrm{S}_{\mathrm{p}} \mathrm{O}_{2}$ for $\mathrm{P}_{\mathrm{a}} \mathrm{O}_{2}$ at levels $\leq 97 \%$ (35). The cutoffs for $\mathrm{S} / \mathrm{F}$ ratio and OSI for diagnosis of ALI/ARDS are summarized in Table 1. From our data, an S/F ratio and OSI within the ARDS category was significantly associated with decreased VFD and IFD. Our data add evidence that $\mathrm{S}_{\mathrm{p}} \mathrm{O}_{2}$-based measurements were reliable in differentiating patients with poorer outcome. The value of having these non-invasive tools to screen for ARDS is to enable early recognition in clinical practice, early institution of proven therapies, allow prediction of outcomes, and lastly facilitate clinical research or epidemiologic studies $(20,36)$.

The OI has an inherent advantage over the $\mathrm{P} / \mathrm{F}$ ratio used in that it incorporates MAP. A higher OI in itself has been shown to independently predict mortality $(1,16-19)$. This was also demonstrated in our study (Table 4). Other centers have used a low OI as criteria for extubation and a high OI for use of HFOV and ECMO $(37,38)$. In agreement with previous studies, we found that the impact of the severity of ARDS on outcome as represented by 
the OI was found to be less predictable within the first $24 \mathrm{~h}$ after diagnosis but was consistent thereafter (16). A P/F ratio within the ARDS range was also associated with mortality after $24 \mathrm{~h}$ of diagnosis. It is very likely that in the early phase of ARDS, therapeutic interventions, such as recruitment maneuvers and the use of optimal positive end expiratory pressure to restore functional residual capacity, as well as response to specific treatment will cause significant improvement in $\mathrm{OI}$ and $\mathrm{P} / \mathrm{F}$ ratio in a subset of children with ARDS.

The strength of this study is that all CICU admissions were individually screened according to the AECC criteria for ARDS to ensure a complete pick up rate. This is also the first study to describe pediatric ARDS in Singapore, which adds to the limited known epidemiology of ARDS within Southeast Asia $(4,39)$. There are several limitations to this study. While all attending physicians in our CICU targeted $6 \mathrm{ml} / \mathrm{kg}$ of tidal volume and limiting peak inspiratory pressures to below $30 \mathrm{~cm} \mathrm{H}_{2} \mathrm{O}$ on conventional mechanical ventilation, there was no strict protocol in our unit for switching between conventional and alternative modes of ventilation; this was left to the discretion of the attending physicians on duty. We found a statistical association between steroid exposure and increased mortality in pediatric ARDS (Table 3). However, the indications and dosages for steroid use were not standardized in our cohort of patients. Moreover, the retrospective nature of this study precludes us from making any cause-and-effect association.

\section{CONCLUSION}

This first description of pediatric ARDS in Singapore demonstrated a high overall mortality. Risk factors for mortality include presence of comorbidities, multiorgan dysfunction, low PF ratio, and high $\mathrm{OI}$ at $24 \mathrm{~h}$ of ARDS. Abnormal $\mathrm{S}_{\mathrm{p}} \mathrm{O}_{2}$-based measurements were reliable alternative markers of poor outcomes in pediatric ARDS.

\section{AUTHOR CONTRIBUTIONS}

Judith Ju-Ming Wong, Tsee Foong Loh, Jan Hau Lee: conception and design of study. Judith Ju-Ming Wong: acquisition of data. Judith Ju-Ming Wong, Tsee Foong Loh, Daniela Testoni, Yee Hui Mok, Joo Guan Yeo, Jan Hau Lee: analysis and interpretation of data. Judith Ju-Ming Wong, Tsee Foong Loh, Daniela Testoni, Yee Hui Mok, Joo Guan Yeo, Jan Hau Lee: drafting and critically revising manuscript.

\section{REFERENCES}

1. Erickson S, Schibler A, Numa A, Nuthall G, Yung M, Pascoe E, et al. Acute lung injury in pediatric intensive care in Australia and New Zealand: a prospective, multicenter, observational study. Pediatr Crit Care Med (2007) 8(4):317-23. doi:10.1097/01.PCC.0000269408.64179.FF

2. Costil J, Cloup M, Leclerc F, Devictor D, Beaufils F, Simeoni U, et al. Acute respiratory distress syndrome (ARDS) in children: Multicenter Collaborative Study of the French Group of Pediatric Intensive Care. Pediatr Pulmonol Suppl (1995) 11:106-7. doi:10.1002/ppul.1950191152

3. Rubenfeld GD, Caldwell E, Granton J, Hudson LD, Matthay MA. Interobserver variability in applying a radiographic definition for ARDS. Chest (1999) 116(5):1347-53. doi:10.1378/chest.116.5.1347

4. Goh AY, Chan PW, Lum LC, Roziah M. Incidence of acute respiratory distress syndrome: a comparison of two definitions. Arch Dis Child (1998) 79(3):256-9. doi:10.1136/adc.79.3.256

5. Flori HR, Glidden DV, Rutherford GW, Matthay MA. Pediatric acute lung injury: prospective evaluation of risk factors associated with mortality. Am J Respir Crit Care Med (2005) 171(9):995-1001. doi:10.1164/rccm.200404-544OC
6. Dahlem P, van Aalderen WM, Bos AP. Pediatric acute lung injury. Paediatr Respir Rev (2007) 8(4):348-62. doi:10.1016/j.prrv.2007.03.001

7. Paret G, Ziv T, Augarten A, Barzilai A, Ben-Abraham R, Vardi A, et al. Acute respiratory distress syndrome in children: a 10 year experience. Isr Med Assoc J (1999) 1(3):149-53.

8. Kneyber MC, Brouwers AG, Caris JA, Chedamni S, Plotz FB. Acute respiratory distress syndrome: is it underrecognized in the pediatric intensive care unit? Intensive Care Med (2008) 34(4):751-4. doi:10.1007/s00134-0081029-4

9. Villar J, Slutsky AS. The incidence of the adult respiratory distress syndrome. Am Rev Respir Dis (1989) 140(3):814-6. doi:10.1164/ajrccm/140.3.814

10. Fowler AA, Hamman RF, Good JT, Benson KN, Baird M, Eberle DJ, et al. Adult respiratory distress syndrome: risk with common predispositions. Ann Intern Med (1983) 98(5 Pt 1):593-7. doi:10.7326/0003-4819-98-5-593

11. Erickson SE, Martin GS, Davis JL, Matthay MA, Eisner MD. Recent trends in acute lung injury mortality: 1996-2005. Crit Care Med (2009) 37(5):1574-9. doi:10.1097/CCM.0b013e31819fefdf

12. Zambon M, Vincent JL. Mortality rates for patients with acute lung injury/ARDS have decreased over time. Chest (2008) 133(5):1120-7. doi:10.1378/chest.072134

13. Martino Alba R, Pfenninger J, Bachmann DC, Minder C, Wagner BP. Changes in the epidemiology of the acute respiratory distress syndrome (ARDS) in children. An Esp Pediatr (1999) 50(6):566-70.

14. Thomas NJ, Shaffer ML, Willson DF, Shih MC, Curley MA. Defining acute lung disease in children with the oxygenation saturation index. Pediatr Crit Care Med (2010) 11(1):12-7. doi:10.1097/PCC.0b013e3181b0653d

15. Ashbaugh DG, Bigelow DB, Petty TL, Levine BE. Acute respiratory distress in adults. Lancet (1967) 2(7511):319-23. doi:10.1016/S0140-6736(67)90168-7

16. Trachsel D, McCrindle BW, Nakagawa S, Bohn D. Oxygenation index predicts outcome in children with acute hypoxemic respiratory failure. Am J Respir Crit Care Med (2005) 172(2):206-11. doi:10.1164/rccm.200405-625OC

17. Seeley E, McAuley DF, Eisner M, Miletin M, Matthay MA, Kallet RH. Predictors of mortality in acute lung injury during the era of lung protective ventilation. Thorax (2008) 63(11):994-8. doi:10.1136/thx.2007.093658

18. Rowan CM, Hege KM, Speicher RH, Goodman M, Perkins SM, Slaven JE, et al. Oxygenation index predicts mortality in pediatric stem cell transplant recipients requiring mechanical ventilation. Pediatr Transplant (2012) 16(6):645-50. doi:10.1111/j.1399-3046.2012.01745.x

19. Rivera RA, Butt W, Shann F. Predictors of mortality in children with respiratory failure: possible indications for ECMO. Anaesth Intensive Care (1990) 18(3):385-9.

20. Khemani RG, Thomas NJ, Venkatachalam V, Scimeme JP, Berutti T, Schneider $\mathrm{JB}$, et al. Comparison of $\mathrm{SpO}_{2}$ to $\mathrm{PaO}_{2}$ based markers of lung disease severity for children with acute lung injury. Crit Care Med (2012) 40(4):1309-16. doi:10.1097/CCM.0b013e31823bc61b

21. Goldstein B, Giroir B, Randolph A. International pediatric sepsis consensus conference: definitions for sepsis and organ dysfunction in pediatrics. Pediatr Crit Care Med (2005) 6(1):2-8. doi:10.1097/01.PCC.0000149131.72248.E6

22. Lopez-Fernandez Y, Azagra AM, de la Oliva P, Modesto V, Sanchez JI, Parrilla J, et al. Pediatric acute lung injury epidemiology and natural history study: incidence and outcome of the acute respiratory distress syndrome in children. Crit Care Med (2012) 40(12):3238-45. doi:10.1097/CCM.0b013e318260caa3

23. Yehya N, Topjian AA, Thomas NJ, Friess SH. Improved oxygenation 24 hours after transition to airway pressure release ventilation or high-frequency oscillatory ventilation accurately discriminates survival in immunocompromised pediatric patients with acute respiratory distress syndrome. Pediatr Crit Care Med (2014) 15(4):e147-56. doi:10.1097/PCC.0000000000000069

24. Santschi M, Randolph AG, Rimensberger PC, Jouvet P. Mechanical ventilation strategies in children with acute lung injury: a survey on stated practice pattern*. Pediatr Crit Care Med (2013) 14(7):e332-7. doi:10.1097/PCC. 0b013e31828a89a2

25. Pinzon AD, Rocha TS, Ricachinevsky C, Piva JP, Friedman G. High-frequency oscillatory ventilation in children with acute respiratory distress syndrome: experience of a pediatric intensive care unit. Rev Assoc Med Bras (1992) (2013) 59(4):368-74. doi:10.1016/j.ramb.2013.02.007

26. Norfolk SG, Hollingsworth CL, Wolfe CR, Govert JA, Que LG, Cheifetz IM, et al. Rescue therapy in adult and pediatric patients with $\mathrm{pH} 1 \mathrm{~N} 1$ influenza infection: a tertiary center intensive care unit experience from April to October 2009. Crit Care Med (2010) 38(11):2103-7. doi:10.1097/CCM.0b013e3181f268f1 
27. Fedora M, Klimovic M, Seda M, Dominik P, Nekvasil R. Effect of early intervention of high-frequency oscillatory ventilation on the outcome in pediatric acute respiratory distress syndrome. Bratisl Lek Listy (2000) 101(1):8-13.

28. Foland JA, Martin J, Novotny T, Super DM, Dyer RA, Mhanna MJ. Airway pressure release ventilation with a short release time in a child with acute respiratory distress syndrome. Respir Care (2001) 46(10):1019-23.

29. The Acute Respiratory Distress Syndrome Network. Ventilation with lower tidal volumes as compared with traditional tidal volumes for acute lung injury and the acute respiratory distress syndrome. N Engl J Med (2000) 342(18):1301-8. doi:10.1056/NEJM200005043421801

30. Schultz TR, Costarino AJA, Durning SM, Napoli LA, Schears G, Godinez RI, et al. Airway pressure release ventilation in pediatrics. Pediatr Crit Care Med (2001) 2(3):243-6. doi:10.1097/00130478-200107000-00010

31. Bernard GR, Artigas A, Brigham KL, Carlet J, Falke K, Hudson L, et al. The American-European Consensus Conference on ARDS. Definitions, mechanisms, relevant outcomes, and clinical trial coordination. Am J Respir Crit Care Med (1994) 149(3 Pt 1):818-24. doi:10.1164/ajrccm.149.3.7509706

32. Ranieri VM, Rubenfeld GD, Thompson BT, Ferguson ND, Caldwell E, Fan E, et al. Acute respiratory distress syndrome: the Berlin Definition. JAMA (2012) 307(23):2526-33. doi:10.1001/jama.2012.5669

33. Ferguson ND, Davis AM, Slutsky AS, Stewart TE. Development of a clinical definition for acute respiratory distress syndrome using the Delphi technique. J Crit Care (2005) 20(2):147-54. doi:10.1016/j.jcrc.2005.03.001

34. Murray JF, Matthay MA, Luce JM, Flick MR. An expanded definition of the adult respiratory distress syndrome. Am Rev Respir Dis (1988) 138(3):720-3. doi:10.1164/ajrccm/138.3.720

35. Rice TW, Wheeler AP, Bernard GR, Hayden DL, Schoenfeld DA, Ware LB. Comparison of the $\mathrm{SpO} 2 / \mathrm{FIO} 2$ ratio and the $\mathrm{PaO} 2 / \mathrm{FIO} 2$ ratio in patients with acute lung injury or ARDS. Chest (2007) 132(2):410-7. doi:10.1378/chest.07-0617
36. Raghavendran K, Napolitano LM. Definition of ALI/ARDS. Crit Care Clin (2011) 27(3):429-37. doi:10.1016/j.ccc.2011.05.006

37. Khan N, Brown A, Venkataraman ST. Predictors of extubation success and failure in mechanically ventilated infants and children. Crit Care Med (1996) 24(9):1568-79. doi:10.1097/00003246-199609000-00023

38. Kamata S, Kitayama Y, Okuyama H, Usui N, Sawai T, Ishikawa S, et al. Entry criteria for extracorporeal membrane oxygenation In neonates with congenital diaphragmatic hernia treated with high-frequency oscillatory ventilation. Pediatr Surg Int (1996) 11(8):532-5. doi:10.1007/BF00626059

39. Norrashidah AW, Azizi BH, Zulfiqar MA. Acute respiratory distress syndrome in a paediatric intensive care unit. Med J Malaysia (1999) 54(2):225-9.

Conflict of Interest Statement: The authors declare that the research was conducted in the absence of any commercial or financial relationships that could be construed as a potential conflict of interest.

Received: 30 May 2014; accepted: 10 July 2014; published online: 25 July 2014. Citation: Wong JJ, Loh TF, Testoni D, Yeo JG, Mok YH and Lee JH (2014) Epidemiology of pediatric acute respiratory distress syndrome in Singapore: risk factors and predictive respiratory indices for mortality. Front. Pediatr. 2:78. doi: 10.3389/fped.2014.00078

This article was submitted to Pediatric Critical Care, a section of the journal Frontiers in Pediatrics.

Copyright (C) 2014 Wong, Loh, Testoni, Yeo, Mok and Lee. This is an open-access article distributed under the terms of the Creative Commons Attribution License (CC BY). The use, distribution or reproduction in other forums is permitted, provided the original author(s) or licensor are credited and that the original publication in this journal is cited, in accordance with accepted academic practice. No use, distribution or reproduction is permitted which does not comply with these terms. 